\title{
Rhodococcus equi venous catheter infection: a case report and review of the literature
}

\author{
Rosalinda Guerrero ${ }^{1}$, Ashish Bhargava ${ }^{2}$ and Zeina Nahleh" ${ }^{1 *}$
}

\begin{abstract}
Introduction: Rhodococcus equi is an animal pathogen that was initially isolated from horses and is being increasingly reported as a cause of infection in humans with impaired cellular immunity. However, this pathogen is underestimated as a challenging antagonist and is frequently considered to be a mere contaminant despite the potential for life-threatening infections. Most case reports have occurred in immunocompromised patients who have received organ transplants (for example kidney, heart, bone marrow) or those with human immunodeficiency virus infection. Infections often manifest as pulmonary involvement or soft tissue abscesses. Bacteremia related to R. equi infections of tunneled central venous catheters has rarely been described.

Case presentation: We report the case of a 63-year-old non-transplant recipient, non-HIV infected Caucasian woman with endometrial carcinoma who developed recurrent bloodstream infections and septic shock due to $R$. equi and ultimately required the removal of her port catheter, a subcutaneous implantable central venous catheter. We also review the medical literature related to human infections with $R$. equi.

Conclusion: $R$. equi should be considered a serious pathogen, not a contaminant, particularly in an immunocompromised patient who presents with a central venous catheter-related bloodstream infection. Counseling patients with central venous catheters who participate in activities involving exposure to domesticated animals is recommended.
\end{abstract}

\section{Introduction}

Rhodococcus equi is an intracellular aerobic, Gram-positive, weakly acid-fast coccobacillus. It has been recognized as an animal pathogen since its original isolation from foals with pneumonia in Sweden in 1923 [1]. Human infection with $R$. equi is rare but is increasingly encountered in patients with human immunodeficiency virus (HIV) infection $[2,3]$, and in solid organ transplant recipients $[1,4,5]$. In most of these cases, there has been a history of contact with farm animals, contaminated soil or manure, in which this organism is commonly found [2]. More than $80 \%$ of cases reported in the English medical literature have pulmonary involvement [5]. The remaining cases involve extrapulmonary sites such as soft tissues, eyes and bone [5-7]. Unfortunately, this pathogen is still underestimated as a formidable adversary in vulnerable patient populations and may be

\footnotetext{
* Correspondence: Zeina.nahleh@ttuhsc.edu

'Department of Internal Medicine, TTUHSC-Paul L Foster School of Medicine, 4800 Alberta Avenue, El Paso, TX 79905, USA

Full list of author information is available at the end of the article
}

discounted by physicians and microbiology laboratories as a contaminant $[2,5]$.

Central venous catheter-related bacteremia due to $R$. equi has been rarely described in the literature and very few cases have been reported in cancer patients [8-10]. Many cancer patients have a special form of central venous catheter known as a port. It consists of a tunneled subcutaneous reservoir with a catheter that connects to a vein (usually the subclavian or the superior vena cava).

We report the case of a 63-year-old woman without a history of organ transplantation or HIV infection, diagnosed with recurrent endometrial carcinoma and mucinous carcinoma of her appendix. During the course of her treatment, she developed recurrent central venous catheter port line infections and septic shock due to $R$. equi, which was cultured from her central venous catheter tip. She was ultimately successfully treated with removal of the catheter and a combination of antibiotics.

\section{Biomed Central}




\section{Case Presentation}

Our patient was a 63-year-old Caucasian woman. She does not smoke cigarettes or drink alcohol. She measures $162.5 \mathrm{~cm}$ in height and weighs 66 kilograms. She had no significant family history. She was initially diagnosed with stage IIIA endometrial carcinoma for which she underwent a hysterectomy and bilateral salpingo ophorectomy followed by pelvic external beam radiation therapy. Two years later, she developed recurrent disease with widespread peritoneal carcinomatosis. An incidental mucinous carcinoma of the appendix was also found during surgical exploration. A central venous catheter port was placed and she received chemotherapy with 5-fluorouracil, leucovorin, and later, irinotecan, capecitabine and oxaliplatin. Her disease progressed despite multiple lines of chemotherapy. During the course of her cancer treatment, our patient also developed a series of complications which included tumorrelated right ureteral obstruction requiring a nephrostomy placement, a sigmoid-vaginal fistula necessitating a colostomy with reversion of the ureteral stent, small bowel obstruction and ileostomy placement, short bowel syndrome and significant weight loss requiring total parenteral nutrition. Our patient recovered gradually and was able to receive subsequent courses of chemotherapy consisting of capecitabine, an oral chemotherapy agent classified as an antimetabolite, and oxaliplatin, an intravenous platinumbased chemotherapy agent classified as an alkylating agent. She developed predictable chemotherapy-related adverse events including diarrhea and hand-foot syndrome, but was able to continue her treatment intermittently. She started developing fever and tenderness at the site of her central venous catheter. Blood cultures were repeatedly negative. Our patient had not received antibiotics within the eight weeks prior to this event. She was not neutropenic. Laboratory results reflected a white blood cell (WBC) count of 12,100 cells $/ \mu \mathrm{L}$, with $87 \%$ neutrophils. Urine and stool examination revealed no abnormal findings. Liver and renal function tests and a chest X-ray were normal. Blood cultures taken from both the central venous catheter and peripheral vein were reported to have no growth after 96 hours incubation. She received empiric vancomycin for two weeks and all signs of infection, including fever, resolved with normalization of WBC count to 7500 cells/ $\mu \mathrm{L}$ and $67 \%$ neutrophils. However, four weeks later, she was admitted to the intensive care unit with a septic shock picture; she had fever, hypotension and tenderness at the site of the central venous catheter, which was then removed. WBC count at this time was 18,400 cells $/ \mu \mathrm{L}$ with 93\% neutrophils. A chest X-ray was negative for pulmonary disease and sputum cultures revealed no microbial growth. She was empirically treated with intravenous ticarcillin/clavulanate, ciprofloxacin and vancomycin. Cultures from the catheter tip as well as blood cultures were submitted for analysis. Two days later, large, irregular mucoid colonies grew and were non-fermentative, distinguishing them from diphtheria colonies. Further incubation grew characteristic salmon-colored colonies of $R$. equi. Microbiologic characteristics of the pathogen were as follows: catalase and urease positive; oxidase, carbohydrate fermentation, mannitol, indole, and citric acid negative; equi factors positive. The cultured organism was found to be resistant in vitro to penicillins and susceptible to erythromycin, gentamicin, tobramycin, vancomycin, imipenem/cilastatin and rifampin. Our patient's antibiotic regimen was modified to include the combination of a $\beta$-lactam antibiotic (imipenem/cilastatin) and a bactericidal antibiotic rifampin. She received imipenem $500 \mathrm{mg}$ intravenously every $8 \mathrm{hrs}$ for 14 days and rifampin $600 \mathrm{mg}$ orally daily. She was discharged on oral rifampin after resolution of her symptoms and two negative blood cultures were obtained. She continued rifampin for twenty-one days and made a full recovery.

\section{Discussion}

The first human case with $R$. equi infection was reported in 1967 in a patient with autoimmune hepatitis who was undergoing treatment with prednisone and 6mercaptopurine [11]. He worked in a stockyard cleaning animal pens and subsequently developed lung and subcutaneous abscesses. Since then, human cases of $R$. equi infection have been described in immunocompromised patients. In this subpopulation of patients, such infections portend high mortality rates and usually require prolonged treatment with multiple antibiotics $[2-8,12]$. In contrast, immunocompetent patients respond well to shorter courses of antibiotics, usually with a single agent $[13,14]$. With the exception of Antarctica, $R$. equi has been identified in soils all over the world, in fresh and sea water and in animals including horses, cattle and wild birds [5]. Human infection can be acquired through inhalation from the soil, inoculation into a wound or ingestion and passage through the alimentary tract $[4,5]$. Other routes of acquisition include nosocomial spread, human colonization and person-to-person transmission [15]. Exposure to domesticated animals such as horses and pigs has been reported in some cases of infection [16]. Our patient may have potentially acquired $R$. equi via exposure to contaminated horse fibers that she uses for her sculptures.

In immunocompromised patients, pulmonary involvement is common, with necrotizing pneumonia being the most frequent presentation [4]. Infection with this organism can be life-threatening and the required treatment is often lengthy. In immunocompetent patients, pulmonary infections are also common and account for $42 \%$ of reported cases [14]. Pulmonary infections have a 
relapsing and remitting course with intermittent bacteremia. The onset of symptoms is usually insidious and may occur over a span of days to weeks, with the patient presenting with fever, non-productive cough, dyspnea and pleuritic chest pain. In some cases, weight loss and hemoptysis, severe enough as to require blood transfusions, have also been noted. Chest radiographs typically reveal pulmonary infiltrates with single or multiple lung segments, mainly in the upper lobes. The radiographic changes bear a striking resemblance to those changes that occur with fungal or tubercular infections. Cavitations, pleural effusions or empyema evolve over a two to four week period [4]. Primary extrapulmonary manifestations are unusual and occur for the most part secondary to hematogenous dissemination. Examples include subcutaneous nodules, brain and renal abscess, lymphadenitis, endophthalmitis and osteomyelitis [17].

Blood cultures are positive in more than one-half of immunocompromised patients with $R$. equi infection compared to only $10 \%$ of normal hosts [18]. Cultures of $R$. equi grow easily under aerobic conditions on non-selective media. Large, irregular, highly mucoid colonies usually grow optimally at $30^{\circ} \mathrm{C}$ and turn to a salmon-pink color within 48 hours [18]. Further incubation leads to release of its red pigment leading to its characteristic salmoncolored colonies. It is non-fermentive which differentiates Rhodococcus from Corynebacterium. $R$. equi is catalaseand urease-positive, and oxidase-negative. Biochemical kits are now available which facilitate identification of R. equi. Our patient had recurrent infections of the central venous catheter which eventually led to its removal. The first set of blood cultures was reported as negative. This may have occurred, in part, due to the fact that infections with $R$. equi are missed because of incomplete or improper identification of the organism [4,5]. In addition, the appearance of $R$. equi as a Gram-positive, weakly acid-fast, diphtheroid-like organism may lead to mistaken identity with a component of the normal flora or a contaminant (a diphtheroid, a micrococcus, or a Bacillus species) [2]. Therefore, a high degree of suspicion should be exercised in susceptible patients. Once $R$. equi is cultured from a sterile site, it should never be considered a contaminating diphtheroid. Septic shock in our patient resulted in part from recurrent infections of the central venous catheter.

Infections with $R$. equi may be life-threatening due to the toxicity of this organism, which is mediated by the presence of large plasmids that encode proteins necessary for virulence inside the cell [19]. This coding process ensures the pathogen's ability to persist and destroy macrophages in the immunocompromised patient [20,21]. Infection of macrophages with $R$. equi results in cytotoxicity, particularly in high bacterial loads [22], and is regulated by virulence-associated plasmids (VAP) [22,23]. More recent work suggests that the type of plasmid that is overcome by a specific $R$. equi strain determines its host specificity, as described by the plasmid-typing scheme known as TRAVAP [23]. TRAVAP is an acronym that represents a polymerase chain reaction (PCR) typing system for $R$. equi in which three plasmid gene markers are evaluated. The first marker is the traA which is found in the conserved conjugal transfer machinery while vapA and vapB are found in two different plasmid subpopulations [23]. In humans and in healthy or afflicted animals with tuberculous-appearing lesions, isolated strains of $R$. equi often possess a VAP coding for a surface-localized $20-\mathrm{kDa}$ protein, and has been referred to as "vapB" due to its high homology to the vapA protein $[19,24]$. VapA and vapB sequences are strongly related to each other (83.6\% identity) [24] and so are the plasmids encoding them [25]. Possession of certain vaps seems to be specific for strains infecting foals, pigs or cattle [19], but it is likely that $R$. equi infections of humans are not determined by particular plasmids but by the basal and chromosomally determined pathogenic potential of $R$. equi [26]. Chromosomally encoded factors involved in $R$. equi virulence have been reported [26,27] The mortality rate for $R$. equi infection among immunocompetent patients is approximately $10 \%$, compared with rates of 20 $55 \%$ among immunocompromised patients, in particular, those with HIV [7]. In humans, R. equi typically resides in, and destroys, macrophages, making it difficult to eradicate especially in immunocompromised patients [12]. This is exemplified in our case. The organism persisted and colonized the central venous catheter after vancomycin therapy, despite therapeutic trough levels, with the organism remaining susceptible to vancomycin. Another factor that may have led to therapeutic failure is the fact that this organism can inhibit macrophage phagosome-lysosome fusion and survives within the cell. Therefore, vancomycin monotherapy may not be the ideal approach to the management of central venous catheter bacteremia with $R$. equi, despite its susceptibility to vancomycin. Combination antimicrobial therapy using bactericidal and intracellularactive agents should be considered. Also, prompt removal of the infected central venous catheter is necessary for adequate infection control, as was the case in our patient.

Therapeutic failure may also occur following a deficient course of treatment. Based on similar experiences with difficult-to-treat organisms like Mycobacterium tuberculosis, and on the fact that distant relapses of rhodococcus infection are common, prolonged therapy is recommended [28]. Although there is no consensus on the optimal duration or regimen of antibiotic treatment, the use of combination therapy may decrease the risk of developing resistance during therapy, which has been described with penicillin and other $\beta$-lactam antibiotics. A carbapenem and a glycopeptide, such as meropenem and vancomycin, are good choices [29]. The combination of macrolides and 
rifampin can also be considered [30]. Other combinations may include a macrolide antibiotic such as erythromycin along with rifampin, vancomycin, fluoroquinolones, aminoglycosides or broad spectrum $\beta$-lactam antibiotics such as imipenem/cilastatin [28-32]. After initial improvement, the patient can be treated with an oral regimen that could include combinations of quinolones, tetracycline, macrolides, and rifampin.

The optimal duration of treatment is unknown. Our patient was successfully treated with a combination of imipenem/cilastatin and rifampin for 14 days, and then continued oral rifampin for 21 days. Due to the intracellular nature of the pathogen, which concentrates in granulocytes and macrophages [31], a prolonged treatment course is advised in immunocompromised patients due to frequent relapses following abbreviated treatment courses. Monotherapy with penicillin and most other $\beta$-lactam antibiotics should be avoided even if $R$. equi is initially sensitive, since $\beta$-lactam resistance may develop during therapy [2]. Also, the minimal inhibitory concentrations of rifampin and erythromycin for $R$. equi strains isolated within the last 10 years have been rising [33] and the emergence of resistant strains to different antibiotics have been reported [34]. These findings highlight the need for strategies other than antibiotic therapy to prevent or treat $R$. equi infections, such as applications of gallium nitrate and vaccination methods [35-41]. In the case of patients taking immunosuppressive therapy following organ transplants, the challenge in the treatment of $R$. equi is the possible interactions of common combination therapy like macrolide antibiotic and rifampin with immunosuppressive agents like tacrolimus or cyclosporine, which are routinely used in these patients. In one case report of a heart transplant patient on immunosuppressive therapy, the excellent response to treatment of $R$. equi occurred following the treatment with a combination of minocycline and a fluoroquinolone [42]. Overall there is no agreement on the treatment of $R$. equi infections in transplant recipients receiving immunosuppressive therapy. A review of the literature and scattered case reports describes different combinations that may prove beneficial in organ transplant recipients, such as a case of a kidney transplant patient who had good results using the combination of carbapenem and teicoplanin [43]. Synergistic combinations of medications are also key, as was demonstrated in human isolates determined by fractional inhibitory concentration indices. Such combinations included: rifampin-minocycline, erythromycin-minocycline, rifampin-erythromycin and imipenem-amikacin [44]. Weinstock and Brown [45] proposed an algorithm for the management of $R$. equi infections in immunocompromised hosts. They recommended an initial treatment with two agents to avoid development of resistance. Vancomycin, carbapenems, quinolones, erythromycin, and rifampin are reasonable first choices. Careful scrutiny of all other medications is mandatory if drug interactions are to be avoided. Later adjustment of therapy based on susceptibility data is recommended. After two weeks of intravenous therapy and attendant clinical improvement, oral antibiotics may be substituted with rifampin, erythromycin, or ciprofloxacin [45]. Six months or more of therapy may be required for lung, bone and joint, and cerebral infections [45]. Novel diagnostic techniques using specific quantitative PCR should be further explored [46,47].

\section{Conclusion}

Human infection with $R$. equi should be considered when evaluating immunocompromised patients with a central venous catheter and fever in the setting of exposure to farm animals. Microbiologists should be familiar with the growth requirements and biochemical properties of this organism. If the pathogen is suspected and identified, the tunneled central venous catheter should be removed to prevent recurrence. Due to the fact that virulent strains of $R$. equi are resistant to phagocytosis and intracellular killing by macrophages, patients should receive a combination of bactericidal and intracellularactive agents that will penetrate cells, such as rifampin and macrolide antibiotics. A prolonged course of an oral antibiotic following initial intravenous therapy has been suggested in the light of frequent relapses with shorter courses. Counseling should be provided to immunocompromised patients inclined to participate in activities involving exposure to domesticated animals or their products.

\section{Consent}

Written informed consent was obtained from the patient for publication of this case report. A copy of the written consent is available for review by the Editor-in-Chief of this journal.

\section{Author details}

'Department of Internal Medicine, TTUHSC-Paul L Foster School of Medicine, 4800 Alberta Avenue, El Paso, TX 79905, USA. ²Department of Internal Medicine, Wayne State University/Detroit Medical Center, 4100 John R, 4HWCRC, Detroit, MI 48201, USA.

\section{Authors' contributions}

ZN developed the manuscript idea, gathered case details, performed the history, physical exam and the treatment of the patient, and co-wrote and edited the manuscript. RG was a major contributor in writing the manuscript. $A B$ reviewed the literature and contributed to writing the manuscript. All authors read and approved the final manuscript.

\section{Competing interests}

The authors declare that they have no competing interests.

Received: 3 December 2009 Accepted: 9 August 2011 Published: 9 August 2011 


\section{References}

1. Magnusson $\mathrm{H}$ : Spezifische infektiose pneumonie beim fohlen: ein neuer eitererreger beim pferd. Arch Wiss Prakt Tierheilkd 1923, 50:22-38.

2. Topino S, Galati V, Grilli E, Petrosillo N: Rhodococcus equi infection in HIVinfected individuals: case reports and review of the literature. AIDS Patient Care STDS 2010, 24(4):211-222

3. Vladusic I, Krajinovic V, Begovac J: [Long term survival after Rhodococcus equi pneumonia in a patient with human immunodeficiency virus infection in the era of highly active antiretroviral therapy: case report and review.]. Acta Med Croatica 2006, 60(3):259-263.

4. Perez MGV, Vassilev T, Kemmerly SA: Rhodococcus equi infection in transplant recipients: a case of mistaken identity and review of the literature. Transpl Infect Dis 2002, 4(1):52-56.

5. Weinstock DM, Brown AE: Rhodococcus equi: an emerging pathogen. Clin Infect Dis 2002, 34(10):1379-1385.

6. Kamboj M, Kalra A, Kak V: Rhodococcus equi brain abscess in a patient without HIV. J Clin Pathol 2005, 58(4):423-425.

7. Napoleao F, Damasco PV, Camello TC, do Vale MD, de Andrade AF, Hirata R Jr, de Mattos-Guaraldi AL: Pyogenic liver abscess due to Rhodococcus equi in an immunocompetent host. J Clin Microbiol 2005, 43(2):1002-1004.

8. Cid A, Jarque I, Salavert M, Martin G, Perez-Belles C, Sanz MA: Recurrent bacteremia caused by Rhodococcus equi in a non-neutropenic patient with acute myeloid leukemia in complete remission. Haematologica 2002, 87(1):ECR03

9. Hsueh PR, Hung CC, Teng LJ, YU MC, Chen YC, Wang HK, Luh KT: Report of invasive Rhodococcus equi infections in Taiwan, with an emphasis on the emergence of multidrug-resistant strains. Clinical Infect Dis 1998, 27(2):370-375

10. Sladeck GG, Frame JN: Rhodococcus equi causing bacteremia in an adult with acute leukemia. South Med J 1993, 86(2):244-246.

11. Golub B, Falk G, Spink WW: Lung abscess due to Corynebacterium equi. Report of first human infection. Ann Intern Med 1967, 66(6):1174-1177.

12. Arya $B$, Hussian $S$, Hariharan S: Rhodococcus equi pneumonia in a renal transplant patient: a case report and review of literature. Clin Transplant 2004, 18(6):748-752.

13. Ulivieri S, Oliveri G: Cerebellar abscess due to Rhodococcus equi in an immunocompetent patient. Case report and literature review. $J$ Neurosurg Sci 2006, 50(4):127-129.

14. Kedlaya I, Ing MB, Wong SS: Rhodococcus equi infections in immunocompetent hosts. Case report and review. Clin infect Dis 2001 32(3):E39-46.

15. Scotton PG, Tonon E, Globbia M, Galluci M, Rigoli R, Vaglia A: Rhodococcus equi nosocomial meningitis cured by levofloxacin and shunt removal. Clin Infect Dis 2000, 3(1):240-242.

16. Gray KJ, French N, Lugada E, Watera C, Gilks CF: Rhodococcus equi and HIV1 infection in Uganda. J Infect 2000, 41(3):227-231.

17. Nasser AA, Bizri AR: Chronic scalp wound infection due to Rhodococcus equi in an immunocompetent patient. J Infect 2001, 42(1):67-78.

18. Verville TD, Huycke MM, Greenfield RA: Rhodococcus equi in humans: 12 cases and a review of the literature. Medicine (Baltimore) 1994, 73(3):119-132

19. Byrne BA, Prescott JF, Palmer GH, Takai S, Nicholson VM, Alperin DC, Hines SA: Virulence plasmid of Rhodococcus equi contains inducible gene family encoding secreted proteins. Infect Immun 2001, 69(2):650-656.

20. Luhrmann A, Mauder N, Sydor T, Fernandez-Mora E, Schulze-Luehrmann J, Takai S, Haas A: Necrotic death of Rhodococcus equi-infected macrophages is regulated by virulence-associated plasmids. Infect Immun 2004, 72(2):853-862.

21. Prescott JF: Rhodococcus equi: an animal and human pathogen. Clin Microbial Rev 1991, 4(1):20-34

22. Takai S, Son WG, Lee DS: Rhodococcus equi virulence plasmids recovered from horses and their environment in Jeju, Korea: 90-kb type II and a new variant, 90-kb type V. J Vet Med Sci 2003, 65(12):1313-1317.

23. Ocampo-Sosa AA, Lewis DA, Navas J, Quigley F, Callejo R, Scortti M, Leadon DP, Fogarty U, Vazquez-Boland JA: Molecular epidemiology of Rhodococcus equi based on tra $\mathrm{A}$, vapA and vapB virulence plasmid markers. J Infect Dis 2007, 196(5):763-769.

24. Letek M, Ocampo-Sosa AA, Sanders M, Fogarty U, Buckley T, Leadon DP, González P, Scortti M, Meijer WG, Parkhill J, Bentley S, Vázquez-Boland JA: Evolution of Rhodococcus equi vap pathogenicity island seen through comparison of host-associated vapA and vapB virulence plasmids. J Bacterio/ 2008, 190(17):5797-5805.

25. Von Bargen K, Haas A: Molecular and infectious biology of the horse pathogen Rhodococcus equi. FEMS Microbiol Rev 2009, 33(5):870-891.

26. Rahman MT, Herron LL, Kapur V: Partial genome sequencing of Rhodococcus equi ATCC 33701. Vet Microbiol 2003, 94(2):43-158.

27. Giguere S, Prescott JF: Clinical manifestations, diagnosis, treatment, and prevention of Rhodococcus equi infections in foals. Vet Microbiol 2006, 56(3-4):313-334.

28. Heidmann P, Madigan J, Watson J: Rhodococcus equi pneumonia: clinical findings, diagnosis, treatment and prevention. Clin Tech Equine Pract 2006, 5(3):203-210

29. Tse KC, Tang SC, Chan TM, Lan KN: Rhodococcus lung abscess complicating kidney transplantation: successful management by combination antibiotic therapy. Transpl Infect Dis 2008, 10(1):44-47

30. Prescott JF: Rhodococcus equi: an animal and human pathogen. Clin Microbiol Rev 1991, 4(1):20-34.

31. Buckley T, McManamon E, Stanbridge S: Resistance studies of erythromycin and rifampin for Rhodococcus equi over a 10-year period. Irish Vet J 2007, 60(12):728-731.

32. Hurley JR, Begg AP: Failure of hyperimmune plasma to prevent pneumonia caused by Rhodococcus equi in foals. Aust Vet J 1995 72(11):418-420.

33. Niwa $H$, Hobo S, Anzai T: A nucleotide mutation associated with fluoroquinolone resistance observed in gyrA of in vitro obtained Rhodococcus equi mutants. Vet Microbiol 2006, 115(1-3):264-268.

34. Harrington JR, Martens RJ, Cohen ND, Bernstein LR: Antimicrobial activity of gallium against virulent Rhodococcus equi in vitro and in vivo. J Vet Pharmacol Ther 2006, 29(2):121-127.

35. Hooper-McGrevy KE, Wilkie BN, Prescott JF: Virulence-associated proteinspecific serum immunoglobulin G-isotype expression in young foals protected against Rhodococcus equi pneumonia by oral immunization with virulent $R$. equi. Vaccine 2005, 23(50):5760-5767.

36. Hurley JR, Begg AP: Failure of hyperimmune plasma to prevent pneumonia caused by Rhodococcus equi in foals. Aust Vet $J$ 1995, 72(11):418-420.

37. Lopez AM, Townsend HG, Allen AL, Hondalus MK: Safety and immunogenicity of a live-attenuated auxotrophic candidate vaccine against the intracellular pathogen Rhodococcus equi. Vaccine 2008, 26(7):998-1009.

38. Machang RS, Prescott JF: Role of anibody to extracellular proteins of Rhodococcus equi in protection against $R$. equi pneumonia in foals. Vet Microbio 1991, 26(4):323-333.

39. Oliveira AF, Ferraz LC, Brocchi M, Roque-Barreira MC: Oral administration of a live attenuated Salmonella vaccine strain expressing the VapA protein induces protection against infection by Rhodococcus equi. Microbes Infect 2007, 9(3):382-390.

40. Pei $Y$, Nicholson V, Woods K, Prescott JF: Immunization by intrabronchial administration to 1-week-old foals of an unmarked double gene disruption strain of Rhodococcus equi strain 103+. Vet Microbiol 2007, 125(1-2):100-110.

41. Prescott JF, Nicholson VM, Patterson MC, Zandona Meleiro MC, Caerino de Araujo A, Yager JA, Holmes MA: Use of Rhodococcus equi virulenceassociated protein for immunization of foals against $R$. equi pneumonia. Am J Vet Res 1997, 58(4):356-359.

42. Kwak EJ, Strollo DC, Kulich SM, Kusne R: Cavitary pneumonia due to Rhodococcus equi in a heart transplant recipient. Transpl Infect Dis 2003, 5(1):43-46.

43. El Karoui K, Guillet C, Sekkal N, Lanternier F, Méchaï F, Hue K, Hiesse C, Mamzer Bruneel MF, Catherinot E, Viard JP, Mainardi JL, Lecuit M, Ferroni A, Lortholary O: Synergistic effect of carbapenem-teicoplanin combination during severe Rhodococcus equi pneumonia in a kidney transplant recipient. Transpl Infect Dis 2009, 11(4):359-362.

44. Nordmann P, Ronco E: In-vitro antimicrobial susceptibility of Rhodococcus equi. J Antimicrob Chemother 1992, 29(4):383-393.

45. Weinstock DM, Brown AE: Rhodococcus equi: an emerging pathogen. Clin Infect Dis 2002, 34(10):1379-1385.

46. Ladron N, Fernandez M, Aguero J, Gonzalez Zorn B, Vazquez-Boland JA Navas J: Rapid identification of Rhodococcus equi by a PCR assay targeting the choE gene. J Clin Microbiol 2003, 41(7):3241-3245. 
47. Rodríguez-Lázaro D, Lewis DA, Ocampo-Sosa AA, Fogarty U, Makrai L, Navas J, Scortti M, Hernández M, Vázquez-Boland JA: Internally controlled real-time PCR method for quantitative species-specific detection and vapA genotyping of Rhodococcus equi. Appl Environ Microbiol 2006, 72(6):4256-4263.

doi:10.1186/1752-1947-5-358

Cite this article as: Guerrero et al:: Rhodococcus equi venous catheter infection: a case report and review of the literature. Journal of Medical Case Reports 2011 5:358.

Submit your next manuscript to BioMed Central and take full advantage of:

- Convenient online submission

- Thorough peer review

- No space constraints or color figure charges

- Immediate publication on acceptance

- Inclusion in PubMed, CAS, Scopus and Google Scholar

- Research which is freely available for redistribution 